Vol.01/ No. 01

Pages: 50-57

https://www.irojournals.com/iroeea

DOI: https://doi.org/10.36548/jeea.2019.1.006

\title{
A DYNAMIC ROUTING MODEL FOR HYBRID ELECTRIC VEHICLES
}

\author{
Dr. Kottilingam \\ Associate Professor \\ School of Computing, \\ SRM University, Chennai, \\ India. \\ Email id: kottilik@srmist.edu.in
}

\begin{abstract}
The recent steady hikes in the prices of the oil/gases and the need for the healthier ecosystem, has led to the larger increase in the interest of the vehicles to move to alternative energy resources that causes a low carbon emission. The hybrid electric vehicle that utilizes both the internal combustion engine and the electrical engine is becoming a predominant option for the vehicle with the low carbon emission than the pure electric vehicle that is restricted due to the limited battery usage. To have an optimal mode of selection of the routes for the hybrid electric vehicle, the paper proposes a method for the identification of minimum delay geographical routing in advance by determining the shortest paths available to the destinations using the prim's minimum spanning tree algorithm, and employing Tabu-Search in enumerating the minimum delay path in order to have a reduced energy usage and a low carbon emission that paves way for the development of the eco-friendly environment.
\end{abstract}

Keywords: Hybrid Electric Vehicles, Carbon Emission, Shortest Path, Minimum Delay Path, Prim’s Minimum Spanning Tree Algorithm and Tabu-Search.

\section{INTRODUCTION}

The need for the alternative energy sources due to the steady increase in the oil rates and to develop an environment that is healthier with the diminished carbon dioxide emission caused by the vehicles has led to the development of the electric and the hybrid electric vehicles [3]. These hybrid electric vehicles are a big leap towards the ecofriendly mobility [8] as they are considered as the extension of the green vehicle routing. The hybrid electric vehicle utilizes both the combustion and the electric engine in it. The hybrid electric vehicle can be categorized into two basic configurations as series hybrid and the parallel hybrid model for the former model the transmission of the power is aided by the both the combustion engines and holds an electricity based drive system, in latter case the power transmission is supported by both the combustion engines and hold a mechanical drive system [7]. The figure.1 below shows the two configurations of the HEV's. The drive system of the hybrid electric vehicle is very complicated and differs for each vehicle. The batteries are usually placed in the center or distributed between the front and the rear of the vehicles as they are heavy and large consuming more space. The remaining components are placed accordingly to achieve a maximum efficiency and a comfort. A switching mechanism is used in the hybrid 
Journal of Electrical Engineering and Automation (EEA) (2019)

Vol.01/ No. 01

Pages: 50-57

https://www.irojournals.com/iroeea

DOI: https://doi.org/10.36548/jeea.2019.1.006

electric vehicle to as two power sources are used. Mostly the hybrid vehicles employ a simultaneous operation of both the electric engine and the internal combustion engine.

(a)

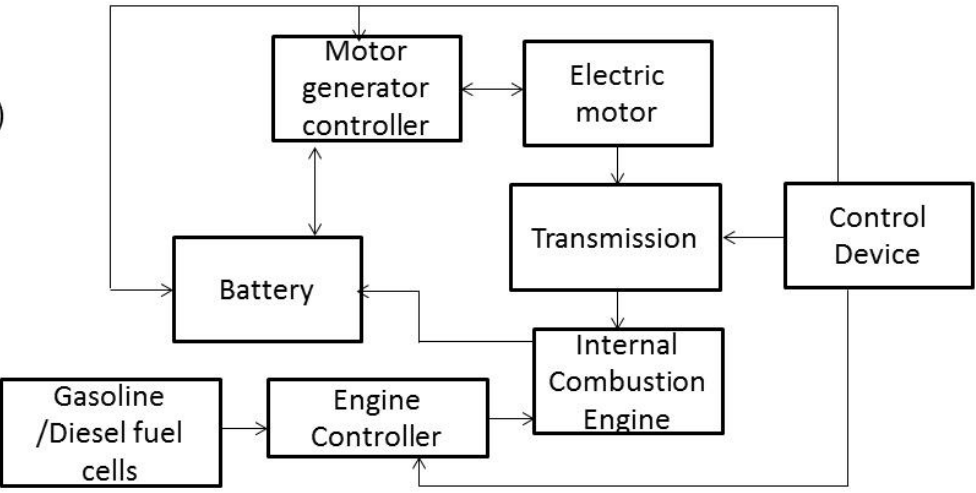

(b)

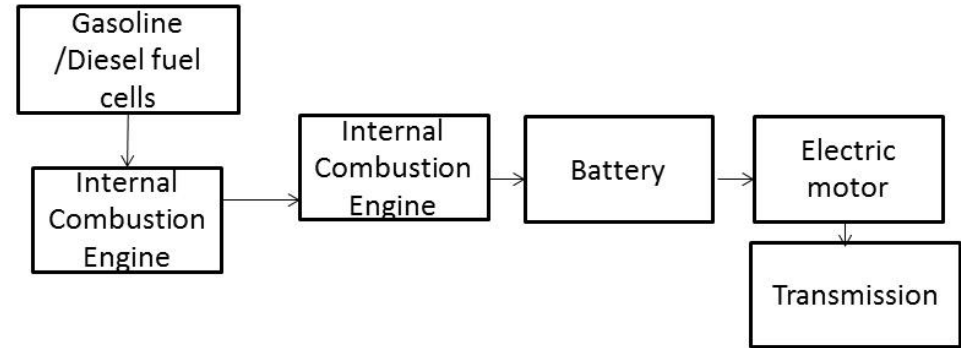

Fig.1. (a) Hybrid Parallel Model. (b) Hybrid Series Model

Using the hybrid electric vehicles the utilization of the electrical engine can be done within the city limits in order to avoid the carbon emission and in the areas that could be covered within a shorter distance so that the HEV's battery could be charged in each destination. But the aim of the paper is to reduce the energy consumption as well as the fuel usage in order to have energy optimized and low carbon emission trip.

So the paper proposes a method for the identification of minimum delay geographical routing in advance by determining the shortest paths available to the destinations using the prim's minimum spanning tree algorithm, and employing Tabu-Search in enumerating the minimum delay path in order to have a reduced energy usage and a low carbon emission that paves way for the development of the eco-friendly environment. 
Journal of Electrical Engineering and Automation (EEA) (2019)

Vol.01/ No. 01

Pages: 50-57

https://www.irojournals.com/iroeea

DOI: https://doi.org/10.36548/jeea.2019.1.006

The paper is organized with the 2. Related works, 3 . The proposed work 4. Results and discussion and 5. Conclusion

\section{RELATED WORKS}

$\mathrm{Mi}$, et al [1], the author provides the principles involved in the developing of the hybrid electric vehicles along with the applications associated with it and the practical perspectives that can be achieved by the utilization of the hybrid vehicle.

Erjavec et al [2] the author provides the details and the fundamentals behind the operation of the various types of vehicles that are available for the personal transportation along with the differences between the vehicles and the advantages of the vehicle that fall under the of the hybrid, electric, and the fuel cell.

Maggetto, et al [3] the primary considerations of the electric and the hybrid electric vehicle along with the structural developments of the hybrid electric vehicle and the electric vehicles and their performances are discussed in the paper

Onori,et al [4] the author presents the energy management issues of the hybrid electric vehicles and the solutions to it by utilizing the real time implementing strategy that ensures an optimal solution.

Baumann, et al [5] the author presents a four stage design of the hybrid electric vehicle proceeding with the development of the hybrid electric vehicle in the first stage followed by a development of a load- leveling vehicle operation strategy in the second stage, In the third stage continues with the system integration and the component sizing and finally in the fourth stage designs a control strategy to achieve a fuel economy. The fig. 2 below shows the power train configuration of the hybrid electric vehicle.

ISSN: 2582-3051 
Journal of Electrical Engineering and Automation (EEA) (2019)

Vol.01/ No. 01

Pages: 50-57

https://www.irojournals.com/iroeea

DOI: https://doi.org/10.36548/jeea.2019.1.006

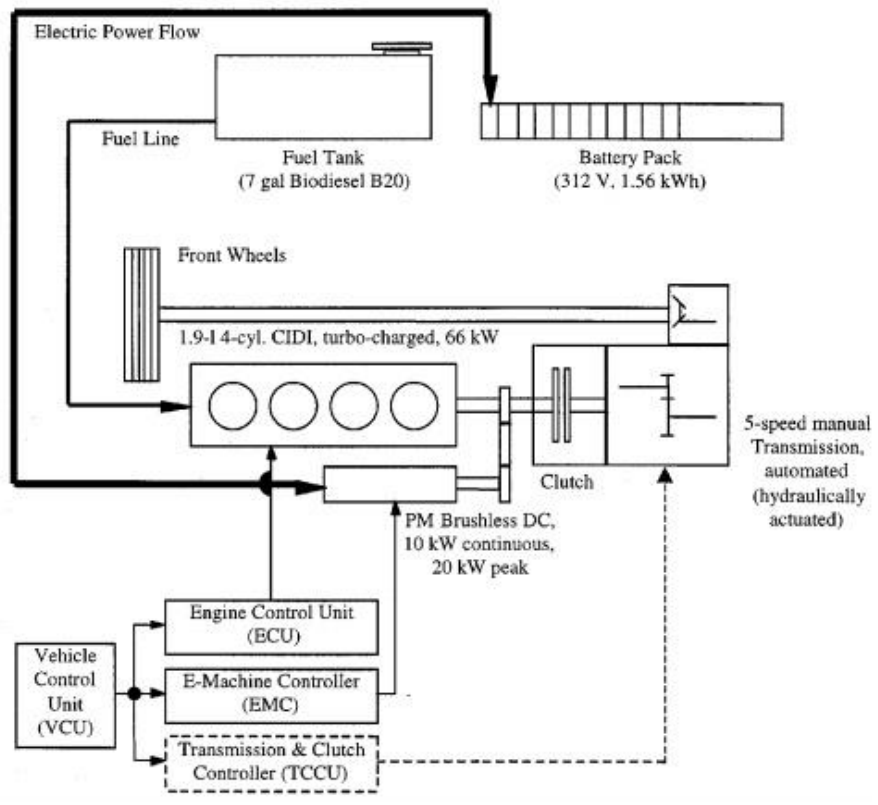

Fig .2 Power Train of the Hybrid Electric Vehicle [5]

Mancini et al [6] the combined integer linear programming and a large neighborhood search based mathematical solution is proposed by the author to address the hybrid vehicle routing problem by constructing the routes with the feasible solutions that provide the complete exploration of the large neighborhood available search within a minimum processing time.

Vincent, et al [7] the simulated annealing with the restarting scheme is proposed in the paper to solve the routing problem in the hybrid electric vehicles. The frame work developed considers the either the utilization of the electric or the fuel based on the availability of the charging station or the fuel station on the path enumerated.

Strehler et al [8] the paper develops frame with the shortest path for the routing of the hybrid electric vehicles, the author studies the several types of the cycles that may occur in the identifying the optimal routing along with the necessary conditions in excluding some of the cycle that doesn't lead to an optimal solution.

Neaimeh, et al [9] the author utilizes the Dijkstra's search algorithm to find the shortest path with the reduced energy consumption for the electric vehicles based on the topography and the traffic conditions to ensures better 
Journal of Electrical Engineering and Automation (EEA) (2019)

Vol.01/ No. 01

Pages: 50-57

https://www.irojournals.com/iroeea

DOI: https://doi.org/10.36548/jeea.2019.1.006

decision making of the routes.

Zeng, et al [10] a stochastic optimal control strategy for the fixed-route driving is presented in the paper to address the energy management in the hybrid electric vehicle. The method proposed is also utilized in the on board implementation in the real time. The fig. 2 below shows the basic hybrid electric vehicle configurations.

Houshmand, et al [11] a CRPTC a "combined routing and a power train control algorithm" to parallely estimate the power consumption and the possible route with the minimum energy consumption is proposed in the paper to provide an eco- routing for the electric vehicles to save energy and the time.

Dascioglu et al [12] the paper presents the literature review on the HEV routing problem to gain knowledge on the current researches available and provides the future enhancements of the research in the field.

Ahn et al [13] the author introduces the analytical approach that serves as a foundation for the increased adoption of the electric vehicle by enumerating the availability of the charging stations utilizing the numerical study to acquire the correlations among the various parameters associated with the region and the technology

\section{PRIM'S MST ALGORITHM FOR SHORTEST PATH ENUMERATION}

The prim's minimum spanning algorithm resembles the shortest path first algorithm and finds the minimum cost spanning tree utilizing a greedy approach. The algorithm considers each node or the vertex as an individual tree and continues to add new nodes to the spanning tree from the given graph.

The basic concept that the prim's algorithm works on is that all the nodes must be connected. Two subsets of the nodes that are disjoint are connected to gather to frame the spanning tree, and the connection must be extended with the nodes with the minimum weighting edge to form a minimum spanning tree. The algorithm below shows the steps involved in finding the shortest path with the minimum length.

STEP1: Create a mset $=\left\{x_{1}, x_{2}, \ldots \ldots . x_{n}\right\}$ that holds the each node that is included in the minimum spanning tree (MST)

STEP2: Allot Key values to all nodes with the first node to be picked up assigned with the value zero.

ISSN: 2582-3051 
Journal of Electrical Engineering and Automation (EEA) (2019)

Vol.01/ No. 01

Pages: 50-57

https://www.irojournals.com/iroeea

DOI: https://doi.org/10.36548/jeea.2019.1.006

STEP3: IF the mset does not include all the nodes that are in the MST THEN

STEP4: Select a node that is not in the mset and has a minimum key value and include it to the mset

STEP5: Update the key values of the nodes that are adjacent to the node selected for every adjacent node, IF the weight of the edge to the selected node is smaller compared to the previous node, THEN update the key value as the weight of selected node to the adjacent node with the minimum edge weight.

Thus using the algorithm with the concept of utilizing the key values ensures in having a minimum weight edge from the cut and enabling to have a minimum length shortest paths for the travel. This idea is utilized in the finding the shortest path in advance for the hybrid electric vehicle to have a minimum energy consumption and thereby reducing the carbon consumption. Further the method is combined with the TABU-Search to identify the minimum delay shortest path among the number of shortest path enumerated.

\subsection{TABU-SEARCH ALGORITHM TO DETERMINE OPTIMAL SOLUTON}

The TABU-Search algorithm combined with the prim's minimum spanning tree enables on to achieve a closer optimal and a satisfying solution. The search begins with the primary solution that are generated randomly by the prim's minimum spanning tree algorithm, to create the new solution the fittest solutions obtained are swapped and the acquired minimum weighted edges are compared to select the more optimal one. To elude the cycles of the repeating the comparison with the same set of solutions and getting trapped to a solution that is a local optimum. Each solution is added to the Tabu list

The new solution that are fittest are obtained until an arbitrary number of the iterations are reached, once the criteria is met the search stops and returns the optimal solution found during the execution. The fig. 3 below gives the algorithm of the Tabu search in enumerating the 'the best' candidate in our case the short path with the minimum delay. 
Journal of Electrical Engineering and Automation (EEA) (2019)

Vol.01/ No. 01

Pages: 50-57

https://www.irojournals.com/iroeea

DOI: https://doi.org/10.36548/jeea.2019.1.006

Input: TabuList updated with the randomly generated results of the PRIM's MST

Output: Solution optimal

Start

Solution $_{\text {optimal }}=$ construct the initial solutions

IF Stopping Conditions not met THEN

Begin

Collect Randomly Generated Results of Prim's MST

Compare Results.

Enumerate fitness

End

IF fitness of the Random Individual > Best Individual THEN

Solution $_{\text {optimal }}=$ Random Individual

ELSE

Solution $_{\text {optimal }}=$ Best Individual

End

End

Fig.3 Tabu-Search Algorithm Combined with the Prim's Algorithm

\subsection{PROPOSED ALGORITHM}

The proposed methodology combines the Prim's minimum spanning tree and the Tabu search for enumeration the shortest path with the minimum delay and reduced cost. Similar to many other heuristics the proposed method also takes two strides that proceed with the initial step of generating random results utilizing the prim's minimum spanning tree. In order to have better enhancement avoiding the situation of getting stuck at the local optima, the Tabu search is combined with the Prim's MST to achieve global optimum solution. The flow chart below in the figure.4 gives the proposed methodology in the enumerating the shortest path $\left(S_{p}\right)$ with the minimum delay $\left(P_{d}\right)$ and minimum cost $\left(P_{C}\right)$ for the hybrid electric vehicle in advance by combining the Prim's MST and the TABU-Search. 
Journal of Electrical Engineering and Automation (EEA) (2019)

Vol.01/ No. 01

Pages: 50-57

https://www.irojournals.com/iroeea

DOI: https://doi.org/10.36548/jeea.2019.1.006

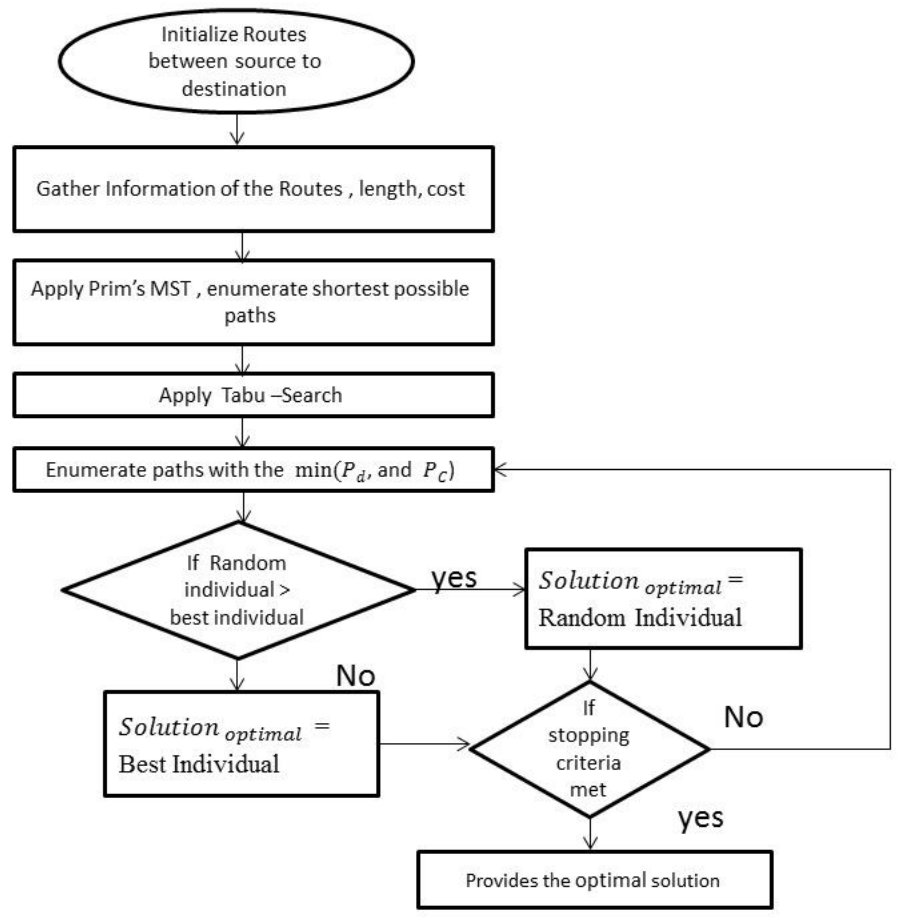

Fig.4 Proposed Algorithm

\section{RESULTS AND DISCUSSION}

The proposed algorithm developed as python codes are implemented using the MATLAB, with the test set up of super micro cloud server with the limited access, 8 AMD Opteron 2.1 gigahertz cores, 16 gigabyte RAM and the windows 2008 operating system. The evaluation of the proposed methodology to identify the quality of the solution obtained in terms of the delay, cost and the sustainability achieved by the low carbon emission from the vehicles.

\begin{tabular}{|l|l|l|l|l|l|l|l|l|l|l|l|}
\hline $\begin{array}{l}\text { Traffi } \\
\text { c } \\
\text { levels }\end{array}$ & $\begin{array}{l}\text { Insta } \\
\text { nce }\end{array}$ & \multicolumn{2}{|l|}{ Delay \% } & \multicolumn{2}{|l|}{ Cost $\%$} & \multicolumn{2}{l|}{$\begin{array}{l}\text { Energy } \\
\text { consumption } \%\end{array}$} & \multicolumn{2}{l|}{$\begin{array}{l}\text { Fuel } \\
\text { consumption \% }\end{array}$} & \multicolumn{2}{l|}{$\begin{array}{l}\text { Carbon } \\
\text { emission } \%\end{array}$} \\
\cline { 2 - 10 } & & $\begin{array}{l}\text { propo } \\
\text { sed }\end{array}$ & $\begin{array}{l}\text { prevai } \\
\text { ling }\end{array}$ & $\begin{array}{l}\text { propo } \\
\text { sed }\end{array}$ & $\begin{array}{l}\text { Prevai } \\
\text { ling }\end{array}$ & $\begin{array}{l}\text { Propo } \\
\text { sed }\end{array}$ & $\begin{array}{l}\text { Prevai } \\
\text { ling }\end{array}$ & $\begin{array}{l}\text { Propo } \\
\text { sed }\end{array}$ & $\begin{array}{l}\text { Prevai } \\
\text { ling }\end{array}$ & $\begin{array}{l}\text { Propo } \\
\text { sed }\end{array}$ & $\begin{array}{l}\text { Prevai } \\
\text { ling }\end{array}$ \\
\hline High & 1 & 35 & 55 & 40 & 70 & 60 & 80 & 30 & 50 & 12 & 20 \\
\hline
\end{tabular}


Journal of Electrical Engineering and Automation (EEA) (2019)

Vol.01/ No. 01

Pages: 50-57

https://www.irojournals.com/iroeea

DOI: https://doi.org/10.36548/jeea.2019.1.006

\begin{tabular}{|l|l|l|l|l|l|l|l|l|l|l|l|}
\hline & 2 & 30 & 50 & 38 & 68 & 54 & 84 & 30 & 50 & 12 & 22 \\
\cline { 2 - 12 } & 3 & 32 & 52 & 39 & 69 & 55 & 85 & 28 & 48 & 11 & 21 \\
\hline \multirow{2}{*}{$\begin{array}{l}\text { Mode } \\
\text { rate }\end{array}$} & 1 & 25 & 45 & 33 & 63 & 50 & 70 & 27 & 47 & 10 & 20 \\
\cline { 2 - 12 } & 2 & 22 & 42 & 32 & 62 & 52 & 72 & 25 & 45 & 10 & 20 \\
\cline { 2 - 13 } & 3 & 20 & 40 & 30 & 60 & 53 & 75 & 24 & 44 & 10 & 20 \\
\hline \multirow{2}{*}{ Low } & 1 & 15 & 35 & 28 & 58 & 45 & 72 & 25 & 45 & 8 & 18 \\
\cline { 2 - 12 } & 2 & 14 & 34 & 27.5 & 57 & 40 & 70 & 25 & 40 & 7 & 17 \\
\cline { 2 - 12 } & 3 & 12 & 32 & 27 & 57 & 42 & 65 & 20 & 40 & 6 & 16 \\
\hline
\end{tabular}

Table.1 Comparison of the Performance Metrics

The table.1 presented above shows the delay acquired the cost of the travel and the measure of the carbon emission and the energy consumption through the short path enumerated on the different conditions of the traffic where high denotes the peak times of the day, moderate denotes the reduced level of traffic in a day and the low denotes the traffic less conditions of the day and under different instances with the value 1 representing the morning time, 2 representing the afternoon and the 3 representing the evening time. The results showed in the table. 1 shows that the proposed method of finding the route in advance for the hybrid electric vehicles ensures a reduced fuel consumption and carbon emission paving way for the development of the ecofriendly environment.

\section{CONCLUSION}

The paper proposes a heuristic optimization algorithm based on prim's minimum spanning tree and the TABUsearch, to identify the minimum delay and the minimum cost shortest paths for the hybrid electric vehicles. The proposed methodology proceeds as two strides with the random generation of the possible shortest paths available between the source and the destination using the prim's MST and determination of the solution that is optimal from the random generations using the TABU-search. Further the qualities of the solutions obtained are evaluated to know the enhancement in the delay, cost, fuel consumption and the carbon emission. The results obtained shows the potential savings achieved in the energy/fuel consumptions and the considerable improvements gained in the carbon emission of the hybrid electric vehicles paving for the development of the environment that is healthier. Further the paper is to continue with the implementation of the proposed method in the customer delivery services within a city. 
Journal of Electrical Engineering and Automation (EEA) (2019)

Vol.01/ No. 01

Pages: 50-57

https://www.irojournals.com/iroeea

DOI: https://doi.org/10.36548/jeea.2019.1.006

\section{References}

[1] Mi, Chris, and M. Abul Masrur. Hybrid electric vehicles: principles and applications with practical perspectives. John Wiley \& Sons, 2017.

[2] Erjavec, Jack. Hybrid, electric, and fuel-cell vehicles. Cengage Learning, 2012.

[3] Maggetto, G., and J. Van Mierlo. "Electric and electric hybrid vehicle technology: a survey." (2000): 1-1.

[4] Onori, Simona, Lorenzo Serrao, and Giorgio Rizzoni. Hybrid electric vehicles: energy management strategies. Vol. 13. Berlin Heidelberg: Springer, 2016.

[5] Baumann, Bernd M., Gregory Washington, Bradley C. Glenn, and Giorgio Rizzoni. "Mechatronic design and control of hybrid electric vehicles." IEEE/ASME Transactions On Mechatronics 5, no. 1 (2000): 58-72.

[6] Mancini, Simona. "The hybrid vehicle routing problem." Transportation Research Part C: Emerging Technologies 78 (2017): 1-12.

[7] Vincent, F. Yu, AAN Perwira Redi, Yosi Agustina Hidayat, and Oktaviyanto Jimat Wibowo. "A simulated annealing heuristic for the hybrid vehicle routing problem." Applied Soft Computing 53 (2017): 119-132.

[8] Strehler, Martin, Sören Merting, and Christian Schwan. "Energy-efficient shortest routes for electric and hybrid vehicles." Transportation Research Part B: Methodological 103 (2017): 111-135.

[9] Neaimeh, Myriam, Graeme A. Hill, Yvonne Hübner, and Phil T. Blythe. "Routing systems to extend the driving range of electric vehicles." IET Intelligent Transport Systems 7, no. 3 (2013): 327-336.

[10]Zeng, Xiangrui, and Junmin Wang. "Stochastic optimal control for hybrid electric vehicles running on fixed routes." In 2015 American Control Conference (ACC), pp. 3273-3278. IEEE, 2015.

[11]Houshmand, Arian, and Christos G. Cassandras. "Eco-routing of plug-in hybrid electric vehicles in transportation networks." In 2018 21st International Conference on Intelligent Transportation Systems (ITSC), pp. 1508-1513. IEEE, 2018.

[12]Dascioglu, Busra Gulnihan, and Gulfem Tuzkaya. "A Literature Review for Hybrid Vehicle Routing Problem." In Industrial Engineering in the Big Data Era, pp. 249-257. Springer, Cham, 2019.

[13]Ahn, Yongjun, and Hwasoo Yeo. "An analytical planning model to estimate the optimal density of charging stations for electric vehicles." PloS one 10, no. 11 (2015): e0141307. 